\title{
Molecular epidemiology of Hepatitis delta virus infection in Minas Gerais state from Brazil, an area outside the hyperendemic region of the Amazon Basin
}

\author{
Cristiane FO Scarponi ${ }^{1,2}$, Erna G Kroon ${ }^{3}$, Deusilene S Vieira ${ }^{4}$, \\ Ana Paula Fernandes ${ }^{1}$, Karina B Gomes ${ }^{1}$, Bruno EF Mota ${ }^{1 /+}$ \\ ${ }^{1}$ Universidade Federal de Minas Gerais, Faculdade de Farmácia, Belo Horizonte, MG, Brasil \\ ${ }^{2}$ Fundação Ezequiel Dias, Instituto Octávio Magalhães, Belo Horizonte, MG, Brasil \\ ${ }^{3}$ Universidade Federal de Minas Gerais, Instituto de Ciências Biológicas, Belo Horizonte, MG, Brasil \\ ${ }^{4}$ Fundação Oswaldo Cruz-Fiocruz, Porto Velho, RO, Brasil
}

BACKGROUND Hepatitis delta virus (HDV) infections in hepatitis B virus (HBV) carriers are the most severe form of viral hepatitis. HDV prevalence is high in the Brazilian Amazon, but studies in other regions of the country are still scarce and often underestimated its prevalence by including a small numbers of individuals.

OBJECTIVE This study aimed to determine the serological prevalence of hepatitis D, the genotypes circulating and to evaluate the associated risk factors for acquisition of HDV in Minas Gerais state, Brazil.

METHODS We screened plasma samples $(n=498)$ from HBV chronic carriers for anti-HD antibodies using a commercial enzyme-linked immunosorbent assay (ELISA) kit. For those samples that were positive for anti-HD antibodies, we performed a reverse transcriptase (RT) nested-polymerase chain reaction (nested-PCR) in order to detect the viral genome and identify the viral genotypes circulating in the state.

FINDINGS The prevalence was $6.22 \%$ (31/498). Blood transfusion was the only risk factor associated with HDV infection [risk ratio: 3.73; 95\% confidence interval (CI): 1.44 to 9.65]. For 26 anti-HD positive patients, HDAg gene sequences were determined and in all patients HDV genotype 1 was found.

CONCLUSIONS This study confirmed the circulation of HDV in Minas Gerais, an area previously considered non-endemic for hepatitis D in Brazil. The prevalence found in this study is much higher when compared to other studies performed in Brazil, probably because the population in our study was selected with minimal bias. Furthermore, in 26 anti-HD positive plasma samples, we were also able to detect the viral genome, indicating that these patients were experienced an active infection at the time of sample collection. These findings emphasise the importance of anti-HD testing in HBV infected individuals, which may contribute to this disease control in Brazil.

Key words: Hepatitis D virus genotype 1 - seroprevalence - molecular epidemiology - Brazil

Hepatitis D virus (HDV or delta virus) is the single specie of the genus Deltavirus. HDV is a defective RNA virus that depends on the hepatitis B virus (HBV) infection to complete its life cycle. The helper function of $\mathrm{HBV}$ is to provide the surface antigen (HBsAg), which HDV use as its envelope protein. Delta virus is classified in at least eight genotypes (one to eight) based on the phylogenetic analysis of the partial sequence of the HDAg ORF or the complete genome (around $1.7 \mathrm{kbp}$ ). Globally, around 250 million individuals live with chronic HBV infection, of whom 15 million also have been superinfected with HDV.(1)

HDV infection is transmitted by the same routes as HBV infection, including sexual contact or parenteral transmission through use of intravenous drugs, surgical

doi: 10.1590/0074-02760190074

Financial support: FAPEMIG (grant number APQ-01202-14),

UFMG intramural funds.

APF, KBG and EGK were supported by CNPq (CNPq Research Fellowship - PQ).

+ Corresponding author: brunofmota@gmail.com

(D) https://orcid.org/0000-0003-0348-4875

Received 22 February 2019

Accepted 08 July 2019 procedures or blood transfusion. (2) Dual infection HDV/ HBV may be acquired in two different ways. In one of these forms, called co-infection, HDV is acquired simultaneously with HBV, coursing as an acute infection, with minimal hepatic damage and total clearance of both viruses in the majority of cases (around 98\%). In the super-infection condition, HDV infection is acquired by an individual already infected by HBV. Approximately $90 \%$ of these patients will develop chronic hepatitis with a high risk to experience severe clinical manifestations as fulminant hepatitis, liver decompensation, cirrhosis and hepatocellular carcinoma. Unlike several effective therapeutic options available for HBV infection, HDVHBV dual infection can only be treated with high doses of interferon alpha. ${ }^{(3)}$

Chronic HBV infection is marked by persistent positivity of HBsAg and can be broadly divided into three different profiles: (i) active hepatitis, which correlates with $\mathrm{HBeAg}$ positivity, elevation of plasmatic transaminases and a decrease in HBV DNA levels, (ii) the inactive carrier state, which is characterised by conversion of $\mathrm{HBeAg}$ to anti-HBe and low or undetectable levels of plasmatic transaminases and HBV-DNA and (iii) the immunotolerant phase, which is characterised by high 
levels of HBV DNA and low levels of plasmatic transaminases. HDV infection is diagnosed by the detection of total or IgM anti-HD antibodies and/or viral RNA in plasma, which is a marker of active viral replication. ${ }^{(2)}$

In Brazil, HDV infection is well documented in the Amazon Basin, where its prevalence is one of the highest in the world. ${ }^{(4,5)}$ On the other hand, there is scant and possibly outdated information on prevalence of HDV infections in other parts of Brazil.(6,7,8) A recent study disclosed the results of a national survey in Brazil, based on the prevalence of anti-HD antibodies. Prevalence values of $1.7 \%$ were reported in the Southeastern region of Brazil and $1.96 \%$ among individuals (1/51) of Minas Gerais state. (9) However, this study did not access the disease status (active viral replication or past infection), virus genotyping and included a limited number of individuals.

Besides epidemiological issues and their impact in control policies, genotyping of HDV is important due to different clinical profiles associated with each genotype. HDV genotype 1 is the most commonly found in Brazil, and was associated with a wide range of clinical manifestations. HDV genotype 3, which is restricted to the Amazon Basin, is associated with a fulminant form of hepatitis, known as Labrea fever. ${ }^{(10)}$ One study described the circulation of HDV genotype 8 in Maranhão state, northeastern of Brazil. ${ }^{(11)}$ However, so far, there is no study describing the molecular epidemiology of HDV in other Brazilian regions, mainly in the dense populated states of the Southeastern region, including Minas Gerais. Therefore, this study aimed to investigate the prevalence, associated factors and the molecular epidemiology of HDV infection in Minas Gerais state, Brazil.

\section{MATERIALS AND METHODS}

Ethical statements - All procedures of this study were performed in accordance with standard ethical rules and were approved by the Research Ethics Committee of Universidade Federal de Minas Gerais (protocol number CAAE, 14253013.7.0000.5149).

Study design and subjects - This cross-sectional epidemiological study enrolled patients attending the Ezequiel Dias Foundation (FUNED), from May 2012 to August 2013. This foundation is the Central Public Health Reference Laboratory, responsible for performing quantification of HBV viral load, after serological diagnosis of this infection in Minas Gerais state. So, all patients that were diagnosed with HBV in the state have their samples sent to FUNED, regardless of the presence of clinical symptoms.

Minas Gerais state is located in the Southeastern region of Brazil. It is the fourth largest state in the country, which occupies a land area of 586,521,235 $\mathrm{km}^{2}$, being divided into 853 municipalities. The estimated population is about $19,600,000$ habitants, being the second most populous state in the country (accessed at www. censo2010.ibge.gov.br).

Only samples from chronic HBV carriers (positive HBsAg for more than six months) were included in the study $(\mathrm{n}=498)$. Demographic, laboratorial and clinical data were obtained from questionnaires answered by the physician responsible for each studied patient.
Serological analyses - Plasma samples, obtained from blood collected in EDTA tube, were stored at $-20^{\circ} \mathrm{C}$ until serological testing. Samples were tested in two independent experiments for the detection of total anti-HD antibodies, using a commercial enzyme immunoassay kit (ETI-AB-2-DELTAK, DiaSorin, Saluggia, Italy), according to the manufacturer's instructions.

Molecular analyses - For samples with detectable total anti-HD antibodies, RNA was extracted using the QIAamp Viral RNA Mini Kit (Qiagen, Hilden, Germany), according to the manufacturer's instructions. The extracted RNA was previously denatured at $95^{\circ} \mathrm{C}$ for 5 min then it was reverse transcribed and the cDNA obtained was amplified in a one-step reverse transcription polymerase chain reaction (RT-PCR), using the QuantiTect Probe RT-PCR kit (Qiagen, Germany), using the outer primers forward 853 IU 5' CGGATGCCCAGGTCGGACC 3' and reverse 1302 OD 5' GGATTCACCGACAAGGAGAG $3{ }^{\prime} \cdot{ }^{(1)}$ The product of the first reaction was used in the second reaction (Nested-PCR) employing inner primers HDV-E 5' GAGATGCCATGCCGACCCGAAGAG 3' and HDV-A 5' GAAGGAAGGCCCTCGAGAACAAGA 3 ${ }^{\prime(2)}$ Reactions conditions were: $95^{\circ} \mathrm{C}$ for $5 \mathrm{~min}$ followed by 30 cycles of $95^{\circ} \mathrm{C}$ for $30 \mathrm{~s}, 55^{\circ} \mathrm{C}$ for $30 \mathrm{~s}$ and $72^{\circ} \mathrm{C}$ for $1 \mathrm{~min}$ with a final step of $72^{\circ} \mathrm{C}$ for $10 \mathrm{~min}$. The PCR products were analysed by electrophoresis in $1 \%$ agarose gels and visualised under UV light, using SYBR Safe stain (Thermo Fisher Scientific, Waltham, MA, United States). The amplified DNA was purified using Wizard ${ }^{\circ}$ SV Gel and PCR Clean-Up System (Promega Corporation, USA), prior to sequencing in ABI Prism 3730 Genetic DNA Analyser using the ABI Prism BigDye Terminator Cycle Sequencing Ready Reaction kit (Applied Biosystems, USA).

Phylogenetic reconstruction - The sequences generated were aligned with standard sequences stored in Gen Bank database (https://www.ncbi.nlm.nih.gov/genbank/) using the algorithm MUSCLE implemented in the EMBL web page (http://www.ebi.ac.uk/Tools/msa/ muscle/). The phylogeny was reconstructed using the maximum likelihood method in PHYML algorithm. ${ }^{(3)}$ The model of nucleotide substitution used was selected by prior analysis using smart model selection (SMS), implemented in PHYML.(4) The resulting trees were visualised using FigTree v.1.2.2 software (http://tree.bio. ed.ac.uk/software/figtree/).

Statistical analysis - Sample size estimation was based on $5 \%$ prevalence rate of HDV, with $2 \%$ margin of error and $95 \%$ confidence level, by StatCalc software, v.7.1.4.0 (Epi Info, CDC, Georgia, USA). Data were analysed using STATA software, v.12.0 (Stata Corp LP, Texas, USA). Continuous variables were described by median and interquartile range (IIQ), being analysed by Mann-Whitney test. Categorical variables were represented as frequency distribution and percentage, being compared using the Chi-square test or Fisher's exact test. Those variables that presented $p$-value below 0.2 (in univariate analysis) were included into the multivariate logistic regression model (Reverse stepwise). Significant differences were considered for $\mathrm{p}$-value $<0.05$. 


\section{RESULTS}

HDV prevalence in Minas Gerais state, Brazil - Of the 498 samples tested, 31 were positive for total anti-HD antibodies, resulting in an overall prevalence of HDV infection of $6.22 \%$ among the chronic HBV carriers. The difference of median age of patients with positive and negative HDV antibody showed a significant association [37 years old (IIQ: 28-44) and 42 (IIQ: 33-52), respectively], in a preliminary univariate analysis $(\mathrm{p}=0.033)$, but no evidence of association was observed after stratification by age range. The proportion of men and women were similar when compared positive and negative HDV antibody patients $(\mathrm{p}=0.872)$. The proportion of HDVinfected men (54.8\%) and women (56.2\%) were similar among the chronic HBV carriers. Most HBV patients, as well as HDV-positive antibody patients had a low educational level ( $\leq 8$ years), measured by years of schooling. However, presence of anti-HD antibodies could not be associated with age range, gender or with the educational level of the patients included in the study (Table I).

Clinical profile of HDV positive cases - Regarding the clinical profile of chronic HBV carriers, there is no difference between the two groups (HBV mono-infected versus HDV/HBV dual infection). More than half of positive HDV/HBV patients (57.14\%) included in our study were inactive carriers, compared to $67.33 \%$ of inactive carriers in negative HDV population, while active hepatitis was reported for $19.02 \%$ of negative HDV patients versus $21.43 \%$ of HDV infected individuals $(p=0.198)$. The fre-

\section{TABLE I}

Sociodemographic characteristics of chronic hepatitis B virus (HBV) patients infected with Hepatitis D virus (HDV) in the state of Minas Gerais, Brazil

\begin{tabular}{lccc}
\hline & \multicolumn{2}{c}{ Total anti-HD antibody } & \\
\cline { 2 - 3 } Variable & $\begin{array}{c}\mathrm{N}^{\mathrm{o}} \text { negative } \\
(\%)\end{array}$ & $\begin{array}{c}\mathrm{N}^{\mathrm{o}} \text { positive } \\
(\%)\end{array}$ & $\mathrm{p}$-value \\
\hline Age group (years) & & $0.068^{a, c}$ \\
\hline $0-19$ & $10(2.14)$ & $0(0.00)$ & \\
\hline $20-39$ & $182(38.97)$ & $20(64.52)$ & \\
\hline $40-59$ & $217(46.47)$ & $9(29.03)$ & \\
\hline$\geq 60$ & $58(12.42)$ & $2(6.45)$ & \\
\hline Gender & & & $0.872^{b}$ \\
\hline Male & $263(56.32)$ & $17(54.84)$ & \\
\hline Female & $204(43.68)$ & $14(45.16)$ & \\
\hline Educational level ${ }^{d}$ & & & $0.647^{a}$ \\
\hline 0 years & $3(1.65)$ & $0(0.00)$ & \\
\hline$\leq 8$ years & $105(57.69)$ & $9(69.23)$ & \\
\hline$>8$ years & $74(40.66)$ & $4(30.77)$ & \\
\hline
\end{tabular}

$a$ : two-tailed $p$-value from Fisher's exact test; $b$ : two-tailed pvalue from Pearson's chi-square test; $c$ : entered into logistic regression for multivariate analysis; $d$ : total patients differ due to missing data. quency of positive anti-HBe marker (25/27, 92.59\%) was higher than positive $\mathrm{HBeAg}(2 / 25,7.41 \%)$ in the infected HDV patients. However, this pattern was not significantly different from the frequencies among uninfected HDV patients $(p=0.402)$. Alanine aminotransferase (ALT) levels in HDV infected individuals were within normal reference values (5-60 U/L) for 19 patients $(70.37 \%)$, but up to two times higher than the reference value in five patients $(18.52 \%)$ and more than two times higher than normal limit (ULN) in three patients $(0.11 \%)$; a similar pattern was detected in uninfected HDV patients $(\mathrm{p}=$ 0.098). These data are shown in Table II.

HBV-DNA was undetectable in $12.90 \%$ of samples from patients with dual HDV-HBV infection. In 74.07\% of these samples, HBV-DNA load was in the range of 20 to $2,000 \mathrm{IU} / \mathrm{mL}$, and in $13.03 \%$ viral load was higher than 2,000 IU/mL, with median viral titer of $2.04 \mathrm{log} \mathrm{IU} /$ mL (IIQ: 1.30-3.25). The median HBV-DNA titer among negative HDV samples was $2.10 \mathrm{log}$ IU/mL (IIQ: 1.30 3.08 ) and was not significantly different between the two groups ( $p=0.906$, data not shown).

Regarding antiviral therapy, 24 out of the 31 infected HDV patients $(77.42 \%)$ reported to be treatment-naïve for HBV infection at the time of the study. Seven patients had a prior history of antiviral treatment, four with entecavir $(4 / 7,57.14 \%)$, one with lamivudine, one with tenofovir and one with adefovir (14.28\% each one). None of them was previously subjected to therapy with Interferon.

Risk factors for HDV infection in Minas Gerais state, Brazil - The analysis of potential risk factors for HDV acquisition in Minas Gerais showed that there is no significant association between HDV infection and the risk factors traditionally described for these infections, such as contact with HBV infected individuals, use of injectable medicines or intravenous drug use, multiple sexual partners and medical procedures like surgery, organ transplantation and hemodialysis. Additionally, no association was found between the detection of anti-HD and any type of institutionalisation or occupation of the patients. However, blood transfusion or blood products recipients was the single variable displaying statistical association with HDV infection among the studied sample $(\mathrm{p}=0.004$, Table III).

To exclude possible confounding factors, all variables that displayed a $\mathrm{p}$-value $<0.2$ in the univariate analysis were included into the logistic regression model. After multivariate analysis, only the variable blood or blood products transfusion history remained statistically associated with HDV infection $(p=0.007)$. The risk ratio of HDV infection for individuals who have received blood products is 3.73 compared to those patients that have not received blood transfusion (95\% CI: 1.44 to 9.65).

HDV nucleic acid detection and phylogenetic analysis - Among the 31 plasma samples that showed anti-HD antibodies, 27 (87.10\%) were also positive for HDV RNA by reverse transcriptase (RT) nested-PCR assay, displaying a specific amplicon of $404 \mathrm{bp}$, corresponding to a partial fragment of HDAg gene (from nucleotide 883 to 1,287 in HDV genome M84917.1). Sequencing and phylogenetic analysis of 26 of these samples showed that all the HDV strains circulating in the Minas Gerais state belong to 
the genotype 1, as supported by high values of bootstrap analysis (Figure). More specifically, our sequences clustered together with viruses detected both from Brazil (Patient_HBV_HDV_HIV_Brazil) as well from the US (US1 and US2). For the missing sample it was not possible to determine the genotype. The sequences used in this study were deposited in GenBank under accession numbers MK101320 through MK101345.

\section{TABLE II}

Comparison of clinical and laboratory profiles between serological Hepatitis D virus (HDV) positive and negative in hepatitis B virus (HBV) chronic carriers in Minas Gerais state, Brazil

\begin{tabular}{|c|c|c|c|}
\hline \multirow[b]{2}{*}{ Variable } & \multicolumn{2}{|c|}{ Total anti-HD antibody } & \multirow[b]{2}{*}{ p-value } \\
\hline & $\begin{array}{c}\mathrm{N}^{\mathrm{o}} \text { negative } \\
(\%)\end{array}$ & $\begin{array}{c}\mathrm{N}^{\mathrm{o}} \text { positive } \\
(\%)\end{array}$ & \\
\hline $\mathrm{IgM}$ anti-HBc$^{d}$ & & & $0.705^{a}$ \\
\hline Negative & $277(88.50)$ & $17(94.44)$ & \\
\hline Positive & $36(11.50)$ & $1(5.55)$ & \\
\hline Anti-HBe $^{d}$ & & & $0.402^{a}$ \\
\hline Negative & $59(14.43)$ & $2(7.40)$ & \\
\hline Positive & $350(85.57)$ & 25 (92.59) & \\
\hline $\mathrm{HBeAg}^{d}$ & & & $0.755^{a}$ \\
\hline Negative & $385(88.51)$ & $25(92.59)$ & \\
\hline Positive & $50(11.49)$ & $2(7.40)$ & \\
\hline $\mathrm{HCV} / \mathrm{HIV}$ coinfection & & & $1.000^{a}$ \\
\hline Negative & $396(93.84)$ & $30(96.77)$ & \\
\hline Positive & $26(6.16)$ & $1(3.23)$ & \\
\hline Chronic HBV stages $^{d}$ & & & $0.198^{a, c}$ \\
\hline Inactive carrier & $301(67.33)$ & $16(57.14)$ & \\
\hline Active hepatitis B & $85(19.02)$ & $6(21.43)$ & \\
\hline Cirrhosis & $32(7.16)$ & $5(17.86)$ & \\
\hline Imunnotolerant & $29(6.49)$ & $1(3.57)$ & \\
\hline ALT levels ${ }^{d}$ & & & $0.098^{a, c}$ \\
\hline$\leq \mathrm{UNL}$ & $351(77.65)$ & $19(70.37)$ & \\
\hline$>\mathrm{UNL}, \leq 2 \mathrm{x} U N L$ & $88(19.47)$ & $5(18.52)$ & \\
\hline$>2 x \mathrm{UNL}$ & $13(2.88)$ & $3(11.11)$ & \\
\hline Cirrhotic & & & $0.078^{b, c}$ \\
\hline No & $394(92.71)$ & $26(83.87)$ & \\
\hline Yes & $31(7.29)$ & $5(16.13)$ & \\
\hline Realised biopsy ${ }^{d}$ & & & $0.501^{a}$ \\
\hline No & $385(90.16)$ & $27(96.43)$ & \\
\hline Yes & $42(9.84)$ & $1(3.57)$ & \\
\hline
\end{tabular}

$a$ : two-tailed p-value from Fisher's exact test; $b$ : two-tailed pvalue from Pearson's chi-square test; $c$ : entered into logistic regression for multivariate analysis; $d$ : total patients differ due to missing data; ALT: alanine aminotransferase; UNL: upper normal limit alanine aminotransferase (ALT $>60 \mathrm{U} / \mathrm{L})$.

\section{DISCUSSION}

This is the first study, to our knowledge, to describe the occurrence of active delta virus infection in Minas Gerais, a state outside the Amazon Basin, in Brazil. Moreover, we have outlined a more detailed epidemiological scenario of HDV infection in a southeastern state of Brazil, with a target population selected with the minimum bias. Our findings confirm the existence of HDV infection in the state, with $6.22 \%$ overall frequency (31/498) for total anti-HD antibodies in the studied population.

The results shown herein differ from most studies performed in this region of Brazil, where no HDV cases were detected. ${ }^{(5,6,7)}$ In a recent national survey, the general prevalence of anti-HD antibodies in chronic HBV carriers in Brazil was 3.2\% and in Minas Gerais state this prevalence was $1.96 \%$, far lower than the prevalence found in our study. ${ }^{(9)}$ The limited sample size and the different criteria for inclusion of participants in other studies could explain, at least in part, the discrepancies found in the HDV prevalence among these studies, leading to underestimated prevalences in general.

Most notably, our results are in agreement with estimations from other non-endemic countries. In a recent study, conducted in Northern California (USA), 42 of the 499 chronic HBV carriers (8\%) tested positive for antiHD antibodies. ${ }^{(12)}$. Other data reported in the literature indicated a prevalence of HDV of $8.3 \%$ in Egyptian patients, ${ }^{(13)} 5.5 \%$ in Belgium, ${ }^{(14)} 6.5 \%$ in Guangdong, China, ${ }^{(15)} 7.1 \%$ in South London ${ }^{(16)}$ and $7.7 \%$ in Tehran, Iran. ${ }^{(17)}$

Another relevant finding is the clinical status of the HDV infected individuals in our study. Traditionally, dual infection of HDV/HBV is marked by high levels of the plasmatic enzyme alanine aminotransferase (ALT) and decreased HBV viral loads. ${ }^{(18)}$ However, the majority of the HDV infected individuals in this study presented ALT levels under normal limits (70.37\%, Table II) and HBV viral loads comparable to that of HBV mono-infected individuals. However, in order to more accurately estimate the long-term effects of HDV-HBV infection in Minas Gerais state, a follow-up study would be more appropriate.

Aiming to identify the probable risk factors for acquisition of HDV infection, the associations between classic behavioral variables for transmission of viral hepatitis versus HDV status were analysed in the studied population. ${ }^{(18,19,20)}$ Our results pointed that blood transfusion history was the single risk factor independently associated with HDV infection among chronic HBV patients in Minas Gerais. This finding is consistent with other studies, in which blood transfusion proved to be a risk factor for HDV infection. ${ }^{(21)}$ Our results showed an association almost four times higher between transfused patients versus not transfused, for hepatitis D infection (Table III). Currently, screening with HBV markers provides a high level of safety in the prevention of HDV infections in blood banks. However, contaminated blood may be eventually transfused, because of false negative detection of HBV infections, due to the ability of HDV to suppress HBV replication, or to the immunological window, during blood bank screening.

An important consideration regarding the treatment of hepatitis D is the availability of a single alternative 
TABLE III

Analysis of risk factors for Hepatitis D virus (HDV) infection in hepatitis B virus (HBV) chronic carriers, Minas Gerais state, Brazil

Total anti-HD antibody

\begin{tabular}{|c|c|c|c|}
\hline Variable $^{d}$ & $\mathrm{~N}^{\mathrm{o}}$ negative $(\%)$ & $\mathrm{N}^{\mathrm{o}}$ positive $(\%)$ & p-value \\
\hline \multicolumn{4}{|c|}{ Dwelling contact with HBV carrier } \\
\hline No & $122(69.71)$ & $9(81.82)$ & $0.317^{a}$ \\
\hline Yes & $53(30.29)$ & $2(18.18)$ & \\
\hline \multicolumn{4}{|c|}{ Sexual contact with HBV carrier } \\
\hline No & $112(84.85)$ & $6(85.71)$ & $0.680^{a}$ \\
\hline Yes & $22(15.15)$ & $1(14.29)$ & \\
\hline \multicolumn{4}{|c|}{ Occupational contact with HBV carrier } \\
\hline No & $160(91.95)$ & $9(90.00)$ & $0.582^{a}$ \\
\hline Yes & $14(8.05)$ & $1(10.00)$ & \\
\hline \multicolumn{4}{|c|}{ Institutionalised patient } \\
\hline No & $263(56.32)$ & $17(54.84)$ & $0.872^{b}$ \\
\hline Yes & $204(46.68)$ & $14(45.16)$ & \\
\hline \multicolumn{4}{|c|}{ Injectable medicines } \\
\hline No & $198(61.49)$ & $13(56.52)$ & $0.637^{b}$ \\
\hline Yes & $124(38.51)$ & $10(43.48)$ & \\
\hline \multicolumn{4}{|c|}{ Tattoo/piercing } \\
\hline No & $284(87.93)$ & $19(82.61)$ & $0.508^{a}$ \\
\hline Yes & $39(12.07)$ & $4(17.39)$ & \\
\hline \multicolumn{4}{|c|}{ Accident with biological material } \\
\hline No & $310(93.66)$ & $20(86.96)$ & $0.197^{a, c}$ \\
\hline Yes & $21(6.34)$ & $3(13.04)$ & \\
\hline \multicolumn{4}{|c|}{ Inhaled drugs users } \\
\hline No & $292(90.40)$ & $20(86.96)$ & $0.484^{a}$ \\
\hline Yes & $31(9.60)$ & $3(13.04)$ & \\
\hline \multicolumn{4}{|c|}{ Acupuncture history } \\
\hline No & $295(94.55)$ & $21(87.50)$ & $0.163^{a, c}$ \\
\hline Yes & $17(5.45)$ & $3(12.50)$ & \\
\hline \multicolumn{4}{|c|}{ Blood transfusion } \\
\hline No & $299(90.06)$ & $17(70.83)$ & $0.004 a^{, b, c, e}$ \\
\hline Yes & $33(9.94)$ & $7(29.17)$ & \\
\hline \multicolumn{4}{|c|}{ Injectable illicit drugs } \\
\hline No & $302(93.21)$ & $20(86.96)$ & $0.224^{a}$ \\
\hline Yes & $22(6.79)$ & $3(13.04)$ & \\
\hline \multicolumn{4}{|c|}{ Surgery procedure } \\
\hline No & $206(64.78)$ & $11(50.00)$ & $0.163^{b, c}$ \\
\hline Yes & $112(35.22)$ & $11(50.00)$ & \\
\hline \multicolumn{4}{|c|}{ Dental procedure } \\
\hline No & $112(39.58)$ & $10(45.46)$ & $0.588^{b}$ \\
\hline Yes & $171(60.42)$ & $12(54.54)$ & \\
\hline \multicolumn{4}{|c|}{ Multiple sex partners } \\
\hline No & $173(57.67)$ & $11(57.89)$ & $0.984^{b}$ \\
\hline Yes & $127(42.33)$ & $8(42.10)$ & \\
\hline \multicolumn{4}{|c|}{ Dialysis procedure } \\
\hline No & $313(93.71)$ & $21(87.50)$ & $0.211^{a}$ \\
\hline Yes & $21(6.29)$ & $3(12.50)$ & \\
\hline \multicolumn{4}{|c|}{ Organ transplant } \\
\hline No & $323(95.56)$ & $19(86.36)$ & $0.089^{a, c}$ \\
\hline Yes & $15(4.44)$ & $3(13.64)$ & \\
\hline
\end{tabular}

$a$ : two-tailed p-value from Fisher's exact test; $b$ : two-tailed p-value from Pearson's chi-square test; $c$ : entered into logistic regression for multivariate analysis; $d$ : total patients differ due to missing data; $e$ : statistically significant $(\mathrm{p}<0.05)$. 


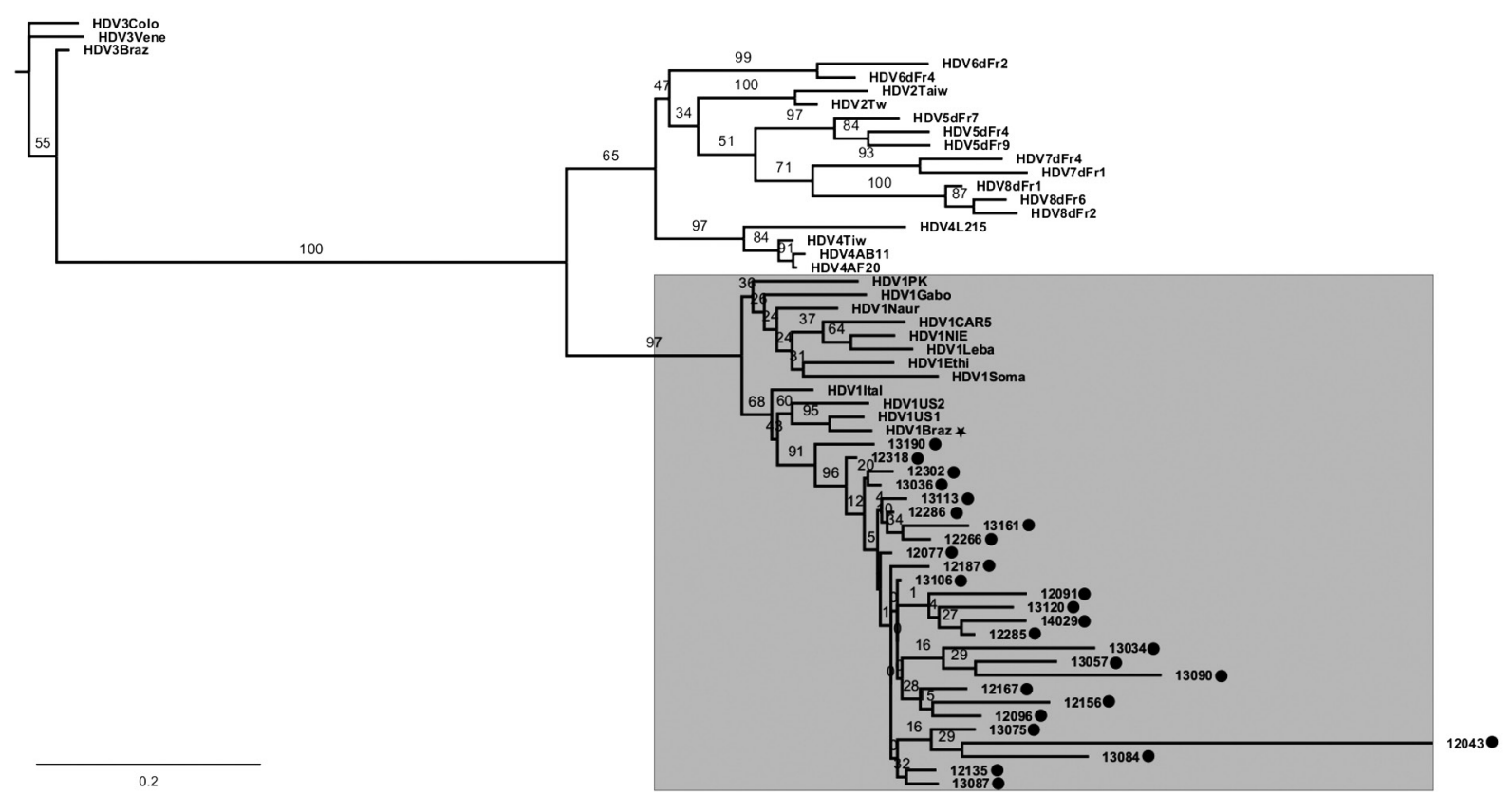

Phylogenetic analysis of Hepatitis D virus (HDV) strains circulating in Minas Gerais state, Brazil. Phylogenetic reconstruction was based in the partial sequence of the HDAg gene. The sequences generated (marked with a circle) were aligned with standard sequences deposited in GenBank database, using the algorithm MUSCLE. The model of nucleotide substitution used (GTR + gamma) was selected using PHYML smart model selection (SMS). The phylogeny was reconstructed using the maximum likelihood method in PHYML algorithm. The resulting trees were visualised using FigTree v.1.2.2 software. The GenBank accession number for the standard sequences used are: HDV1PK (JN400348.1), HDV1Gabo (EU035520.1), HDV1Naur (M58629), HDV1CAR5 (JX888135.1), HDV1NIE (JX888121.1), HDV1Ethi (U81989.1), HDV1Soma (U81988.1), HDV1US1 (D01075), HDV1US2 (L22066), HDV1Braz (HQ686061), HDV1Ital (X04451), HDV1Leba (M84917), HDV2Tw (AF104264), HDV2Taiw (U19598), HDV3Vene (AB037948.1), HDV3Colo (EU287872.1), HDV3Braz (KC590319.1), HDV4AB11 (AB118847.1), HDV4AF20 (AF209859.1), HDV4L215 (AB088679), HDV4Tiw (AF018077), HDV5dFr7 (AX741154), HDV5dFr4 (AX741149), HDV5dFr9 (AX741159), HDV6dFr4 (AX741164), HDV6dFr2 (AJ583887), HDV7dFr4 (AX741164), HDV7dFr1 (AJ583885), HDV8dFr1 (AM183330.1), HDV8dFr2 (AM183327.1), HDV8dFr6 (AX741169). Highlighted in gray is the clade corresponding to HDV genotype 1. The other Brazilian HDV-1 sequence deposited in Gen Bank (HDV1Braz) is marked with a star.

— interferon alpha (IFN- $\alpha$ ), which has antiviral activity by inhibiting mRNA and protein synthesis, besides promoting widespread activation of the immune system.(3) In accordance with prior studies, nucleoside and nucleotide analogs used in the treatment of HBV infection are ineffective against HDV. Given that active HDV infection was not previously suspected, based in the underreported or outdated epidemiological data, it is not surprising that none of the patients have been previously tested for HDV and consequently none of them have received IFN- $\alpha$. Based on our survey, among those receiving treatment with other antiviral drugs, three patients have not reached a sustained virological response or changed medication during treatment (data not shown). Thus, in Minas Gerais, HDV infected patients are not receiving the most appropriate therapy for HBV-HDV infections.

Viral RNA was detected in 27 out of $31(87.10 \%)$ patients with positive total anti-HD antibodies. This finding indicates that most of the patients are experiencing an active infection with delta virus. The amplified cDNA was successfully sequenced for 25 patients. Phylogenetic analyses using the maximum likelihood method showed that all these patients are infected with HDV genotype 1 (Figure). Specifically, the sequences generated in this work are in the same clade that strains isolated in Brazil from a patient with a triple HBV-HDV-HIV infection ${ }^{(22)}$ and strains derived from North American patients with fulminant liver disease. ${ }^{(23,24)}$ These three HDV strains, in its turn, are closely related to European HDV. ${ }^{(22,23,24)}$ This fact suggests that Brazilian genotype 1 strains (and other New World genotype 1 strains) may have derived from European HDV-1 strains. This genotype is spread worldwide and may lead to a wide variety of clinical presentations in infected patients. In our study, most patients presented clinically as inactive carriers, with anti-HBeAg seroconversion and low levels of plasmatic ALT and HBV genomic DNA. This is an important aspect, since the suspicion of HDV infection is often based on the presence of advanced liver disease in individuals that came from endemic areas (such as the Brazilian Amazon).

In conclusion - The findings described herein demonstrate for the first time that HDV genotype 1 is circulating in Minas Gerais state, Brazil and that blood transfusion is the most important risk factor for acquisition of HDV infection in the state. This study contributes to improve the current understanding of the epidemiological and clinical aspects of hepatitis D in Brazil, emphasising the relevance of future research in other areas beyond the Amazon Basin. Moreover, it suggests for the need of better management of diagnosis, treatment and follow-up of chronic HBV carriers and implementation of focused public health actions and control measures in the localities with high number of cases. 


\section{AUTHORS' CONTRIBUTION}

CS - Designed and performed the experiments, analysed the results and wrote the manuscript; EK and DV - provided essential reagents and wrote the manuscript; APF and KG provided essential reagents, analysed the results and wrote the manuscript; BM - project coordinator, designed the experiments, analysed the results and wrote the manuscript.

\section{REFERENCES}

1. Hughes SA, Wedemeyer H, Harrison PM. Hepatitis delta virus. Lancet. 2011; 378(9785): 73-85.

2. Rizzetto M. Hepatitis D virus: introduction and epidemiology. Cold Spring Harb Perspect Med. 2015; 5(7): a021576.

3. Lempp FA, Ni Y, Urban S. Hepatitis delta virus: insights into a peculiar pathogen and novel treatment options. Nat Rev Gastroenterol Hepatol. 2016; 13(10): 580-9.

4. Crispim MAE, Fraiji NA, Campello SC, Schriefer NA, Stefani MMA, Kiesslich D. Molecular epidemiology of hepatitis B and hepatitis delta viruses circulating in the western Amazon Region, North Brazil. BMC Infect Dis. 2014; 14(1): 94.

5. Braga WSM, Castilho MC, Borges FG, Leão JRDT, Martinho ACS, Rodrigues IS, et al. Hepatitis D virus infection in the western Brazilian Amazon - far from a vanishing disease. Rev Soc Bras Med Trop. 2012; 45(6): 691-5.

6. Ferraz ML, Vilela MP, Silva AE, Paiva ER. [Serological markers for hepatitis B virus and delta antibody in Brazilian male homosexuals]. Rev Paul Med. 1985; 103(5): 228-30.

7. Ribeiro LC, Souto FJ. [Hepatitis delta in the state of Mato Grosso, Brazil: report of 5 cases]. Rev Soc Bras Med Trop. 2000; 33(00378682): 599-602.

8. Strauss E, Gayotto LC, da Silva LC, Alves VA, Carrilho F, Chamone DA, et al. Unexpected low prevalence of delta antibodies in the east Amazon Region and São Paulo: evidence for regional differences in the epidemiology of delta hepatitis virus within Brazil. Trans R Soc Trop Med Hyg. 1987; 81(1): 73-4.

9. Lago BV, Mello FCA, Barros TM, Mello VM, Villar LM, LewisXimenez LL, et al. Hepatitis D infection in Brazil: prevalence and geographical distribution of anti-delta antibody. J Med Virol. 2018; 90(8): 1358-63.

10. Botelho-Souza LF, Vieira DS, dos Santos AO, Pereira AVC, Villalobos-Salcedo JM. Characterization of the genotypic profile of hepatitis delta virus: isolation of HDV genotype-1 in the western Amazon Region of Brazil. Intervirology. 2015; 58(3): 166-71.

11. Santos MDC, Gomes-Gouvêa MS, Nunes JDC, Barros LMF, Carrilho FJ, Ferreira ASP, et al. The hepatitis delta genotype 8 in Northeast Brazil: the North Atlantic slave trade as the potential route for infection. Virus Res. 2016; 224: 6-11.
12. Gish RG, Yi DH, Kane S, Clark M, Mangahas M, Baqai S, et al. Coinfection with hepatitis B and D: epidemiology, prevalence and disease in patients in Northern California. J Gastroenterol Hepatol. 2013 ; 28(9): 1521-5.

13. Fouad R, Abdo M, Eldeen HG, Sabry D, Atef M, Ahmed R, et al. Influence of delta virus infection on the virologic status in Egyptian patients with chronic hepatitis B virus genotype D. J Med Virol. 2016; 88(5): 837-42.

14. Ho E, Deltenre P, Nkuize M, Delwaide J, Colle I, Michielsen P, et al. Coinfection of hepatitis B and hepatitis delta virus in Belgium: a multicenter BASL study. Prospective epidemiology and comparison with HBV mono-infection. J Med Virol. 2013; 85(9): 1513-7.

15. Liao B, Zhang F, Lin S, He H, Liu Y, Zhang J, et al. Epidemiological, clinical and histological characteristics of $\mathrm{HBV} / \mathrm{HDV}$ co-infection: a retrospective cross-sectional study in guangdong, China. PLoS One. 2014; 9(12): e115888.

16. Cross TJS, Rizzi P, Horner M, Jolly A, Hussain MJ, Smith HM, et al. The increasing prevalence of hepatitis delta virus (HDV) infection in South London. J Med Virol. 2008; 80(2): 277-82.

17. Tahaei SME, Mohebbi SR, Azimzadeh P, Behelgardi A, Sanati A, Mohammadi P, et al. Prevalence of hepatitis D virus in hepatitis $B$ virus infected patients referred to Taleghani hospital, Tehran, Iran. Gastroenterol Hepatol Bed Bench. 2014; 7(3): 144-50.

18. Kushner T, Serper M, Kaplan DE. Delta hepatitis within the veterans affairs medical system in the United States: prevalence, risk factors, and outcomes. J Hepatol. 2015; 63(3): 586-92.

19. Gheorghe L, Csiki IE, Iacob S, Gheorghe C, Trifan A, Grigorescu $\mathrm{M}$, et al. Hepatitis delta virus infection in Romania: prevalence and risk factors. J Gastrointestin Liver Dis. 2015; 24(4): 413-21.

20. Motamedifar M, Taheri M, Lankarani KB, Gholami M, Lari MA, Faramarzi H, et al. The prevalence and risk factors of hepatitis delta virus in HIV/HBV co-infected patients in Shiraz, Iran, 2012. Iran J Med Sci. 2015; 40(5): 448-53.

21. Amini N, Alavian SM, Kabir A, Hosseini SYS, Andabili SHA. Clinical features and seroepidemiology of anti-HDV antibody in patients with chronic hepatitis B virus infection in Iran: a metaanalysis. Hepat Mon. 2011; 11(12): 960-7.

22. Mendes-Correa MC, Gomes-Gouvêa MS, Alvarado-Mora MV, da Silva MH, Lázari C, Cavalcanti NCS, et al. Hepatitis delta in HIV/ HBV co-infected patients in Brazil: is it important? Int J Infect Dis. 2011; 15(12): e828-32.

23. Casey JL, Brown TL, Colan EJ, Wignall FS, Gerin JL. A genotype of hepatitis D virus that occurs in northern South America. Proc Natl Acad Sci USA. 1993; 90(19): 9016-20.

24. Saldanha JA, Thomas HC, Monjardino JP. Cloning and sequencing of RNA of hepatitis delta virus isolated from human serum. J Gen Virol. 1990; 71(Pt 7): 1603-6. 